\title{
ÉTICA NA PESQUISA CIENTÍFICA
}

A SOCIEDADE É COMPOSTA POR DIFERENTES TIPOS DE CONHE-

CIMENTO, ENTRETANTO O CIENTÍFICO É UM DOS MAIS RELEVAN-

TES EM NOSSO DIA A DIA. ASSIM, ÉTICA E MORAL DEVEM PRIO-

RIZAR OS INTERESSES SOCIAIS, E NÃO INDIVIDUAIS

PETER KEVIN SPINK, professor da FGV-EAESP, peter.spink@fgv.br

A tarefa primária da pesquisa científica é a produção do conhecimento. Seja ele de inspiração teórica, tecnológica ou prática, o conhecimento produzido pela ciência não é o único que utilizamos. Vivemos sob uma vasta ecologia de maneiras de produzir e fazer circular saberes, incluindo o óbvio (que não é óbvio) senso comum, os saberes tradicionais de múltiplas fontes e culturas, e os saberes práticos, com sua extensa biblioteca. Entretanto, quando pensamos sobre nosso cotidiano de equipamentos eletrônicos, redes sem fio, leite pasteurizado, remédios, motores de combustão interna, fibras artificiais e sacolinhas plásticas, temos que aceitar que o conhecimento científico, produto da pesquisa empírica, é, certamente, o mais barulhento.

\section{ÉTICA NAS DECISÕES}

Apesar das diferenças, todas as maneiras de se produzir conhecimento têm um único fim prático: contribuir para nosso dia a dia. Em outras palavras, sua finalidade é social. Quando investimos nossos esforços para avançar o conhecimento, fazemos porque algo chamou a nossa atenção, seja um problema, um desafio ou alguma coisa que desejamos aperfeiçoar. Não é a realidade lá fora que determina o que precisamos saber, mas nós mesmos. E, se decidimos o que é um problema, também decidimos o que não é. Portanto, ao embarcar em um empreendimento científico, 
assumimos simultaneamente questões éticas (como pensamos que a vida deve ser vivida) e morais (o que entendemos como bem e mal, justo e injusto). A expressão "simultânea" refere-se não somente ao momento temporal, mas à proposta filosófica de que ética e moral se constituem mutuamente, na medida em que a busca por compreender o que é viver nos leva ao terreno prático de como tratamos o outro, e o debate entre o justo e o injusto leva-nos à reflexão sobre justiça como tal.

\section{ÉTICA NA PESQUISA}

Quando me refiro a ética na pesquisa científica hoje, em plena modernidade tardia, a frase parece ter sentido óbvio. Porém, essa obviedade é bastante recente. A ideia de ética acompanha o mundo ocidental, pelo menos, desde a discussão sobre valores sociais nas cidadesestados da confederação grega, que serviu de agenda para os questionamentos de Sócrates. Já o mesmo não é válido para a combinação do termo com o campo científico, que soaria estranha para os fundadores da Sociedade Real em Londres, no ano de 1661, cujo lema nullius in verba expressou a determinação de verificar proposições científicas com base no apelo aos fatos que, para os seguidores de Francis Bacon, eram externos e pertencentes à natureza. Mesmo em plena modernidade do sécu-

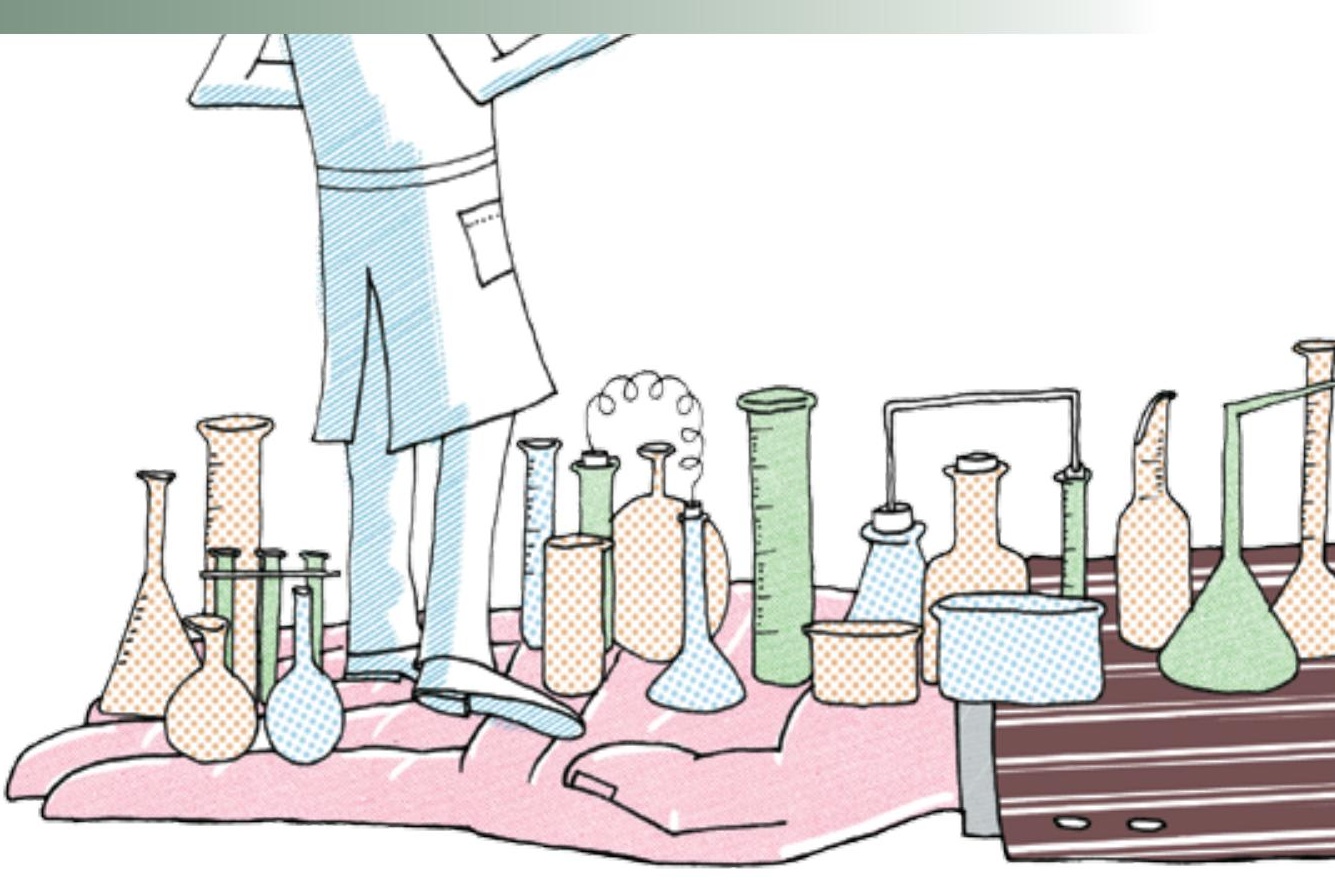

lo XIX, os tormentos morais que Charles Darwin enfrentava, por exemplo, habitaram um plano totalmente diferente das suas coleções de espécies e suas observações microscópicas. Presumiu-se que a discussão dos fatos era uma atividade séria entre pessoas sérias.

Mesmo para as gerações recentes de pesquisadores, atentos aos debates entre filósofos e historiadores das ciências sobre o que é ciência, a sugestão da necessidade de discutir a ética na pesquisa provavelmente produziria uma reação similar. A ética da atividade científica era presumida como natural porque, tal como os demais saberes (práticos, tecnológicos, sociais ou artesanais), era feita, em grande parte, por pessoas honestas e sinceras que gostavam do que faziam, que aceitavam os limites da negociação da verdade e reagiam contra proposições que consideravam insustentáveis. em um trabalho

questões éticas

e morais

simultaneamente

\section{Ao embarcar}

\section{científico,}

\section{assumimos}


É essa prática de lidar com questões éticas e morais como parte do cotidiano que está sendo questionada hoje, como atestam os diversos códigos de conduta para pesquisa e publicação científica produzidos nos últimos anos. Somente em 2011, no Brasil, tivemos o Código de Boas Práticas Científicas da Fundação de Amparo à Pesquisa do Estado de São Paulo (Fapesp), o relatório e recomendações da Comissão de Integridade de Pesquisa do Conselho Nacional de Pesquisa Científica (CNPq) e a consulta pública sobre a revisão da Resolução 196/1996 do Conselho Nacional de
Saúde, que trata da ética em pesquisa em seres humanos. Há códigos e recomendações em outros países que já ensaiam iniciativas em âmbito regional (por exemplo, The European Code of Conduct for Research Integrity, produzido pela European Science Foundation). Ao ler esses e outros documentos, parece que, de maneiras distintas, pesquisadores, gestores, editores, usuários e financiadores estão chegando à conclusão de que a caótica cultura democrática e coletiva que sustentava as diferentes comunidades científicas e garantia a circulação do saber está com sérias dificuldades de enfrentar, pelo menos, três desafios.

\section{DESAFIOS}

O primeiro desafio decorre da crescente subordinação de certas áreas científicas a poderosos grupos econômicos privados que têm os meios para direcionar atividades e criar exclusividade. Os estímulos econômicos e a pressão por produtos impactam de diferentes maneiras na produção de conhecimento. Biopirataria, uso de populações vulneráveis para ensaios clínicos, reformatação criativa (tweaking) de resultados para facilitar a corrida do laboratório para o mercado e o abuso da linguagem científica para apoiar propostas de base ideológica, são todos fatores propulsionadores de uma preocupação crescente, expressa em questões éticas sobre como fazemos as ciências.

O segundo desafio vem, em parte, do impacto do primeiro na prática da comunicação científica. Aqui, o desafio maior é a dificuldade em lidar, de maneira séria e responsável, com as pressões criadas pelos próprios pesquisadores na busca por recursos, posições acadêmicas, e pelas universidades, preocupadas com suas colocações em um cenário totalmente novo de avaliação nacional e internacional. A preocupação com a produtividade acadêmica é, em si, salutar, afinal somos todos, de uma maneira ou outra, usuários de fundos ou benefí- 
cios públicos. A dificuldade é entender o que a produtividade representa diante uma tendência quase hegemônica de medi-la pela quantidade de publicações em revistas e editoras de excelência, que, por sua vez, também competem entre si em termos de fator de impacto. A quase inevitável consequência tem sido um aumento de publicações compartilhadas entre múltiplos autores, programas de pesquisa cujos resultados são fatiados em múltiplos artigos e exemplos crescentes de plágio e autoplágio. Aqui, a questão ética é sobre como relatar ou comunicar as ciências.

Em terceiro lugar, e não menos importante, são as pressões, para ser mais transparente, sobre as situações em que a expressão "a ciência nos mostra que..." é utilizada, seja diretamente - nas páginas de ciência nos jornais diários - ou indiretamente pelo uso da expressão "ponto de vista técnico". Somos, assim, induzidos a aceitar que a ciência, como modo de produzir conhecimento, deve ocupar um lugar privilegiado no direcionamento de decisões e recursos públicos. Aqui, a questão ética é sobre a responsabilidade que as comunidades científicas têm para com a sociedade da qual fazem parte, em termos dos limites das suas certezas. Em outras palavras: sobre o que e até onde as ciências podem ou devem opinar?

\section{RELEVÂNCIA DA ÉTICA NA PESQUISA}

Podemos questionar se essa nova cultura de códigos de ética será capaz de substituir a prática anterior. Certamente, a experiência da humanidade no campo do Direito sugere que o convívio entre códigos e a dinâmica da vida cotidiana nunca foi tranquilo e que as tentativas de enquadrar o bom senso permanecem sempre parciais. A ética e a moral são dinâmicas, partes fundadoras e componentes ativos da vida social. Nesse contexto, é importante notar que as recomendações e exigências presentes nesses documentos são produtos de diferentes versões e posições sobre ciência. São, consequentemente, polissêmicos em seus sentidos. A seu favor, ao apontar para práticas desejadas e indesejadas, levam a discussão sobre os saberes para a praça pública. Na direção contrária, precisamos reconhecer que seguir regras éticas não necessariamente implica viver - no sentido performático - de modo ético e que talvez a ciência seja séria demais para deixar a determinação dos seus rumos e práticas nas mãos dos cientistas. É aqui que precisamos nos perguntar sobre um quarto desafio, refiro-me à questão sobre: o que investigar?
Na sua longa e difícil luta para ser considerada um agir válido entre as artes do conhecer, a ciência, com muita razão, sempre argumentou sobre a importância da liberdade de cada investigador seguir seu próprio nariz. Não sou o primeiro e, certamente, não serei o último a apontar que - de maneira curiosa - esse princípio é frequentemente suspenso em tempos de guerra (quando as ciências se envolvem ativamente nas questões de defesa nacional) e raramente em tempos de paz. Quando acontece, como na década de 1980, com a mobilização em torno do HIV/ AIDS, o resultado é uma contribuição significativa à solidariedade humana e uma demonstração de que, sim, é possível articular a competência e o protagonismo das ciências e dos demais saberes de maneira democrática para assumir a responsabilidade moral de atender os interesses coletivos.

Em suma, a ética na pesquisa científica não se reduz ao como fazer, como comunicar e aos limites do que dizer. Antes de mais nada, refere-se ao que foi investigado e para quem - eis a "questão" que precisamos aprender a desembrulhar. Se não, corremos o risco de ter uma ciência corretíssima - com procedimentos auditados, códigos de publicação e manuais de melhores práticas -, mas moralmente irresponsável. 